\title{
Research on Key Technology and Technical and Economic Indicators of 220kV Prefabricated Cabin Substation
}

\author{
YANG Chen*1, ZHAO Haibo ${ }^{1}$, HE Shixuan ${ }^{1}$, LIU Huiqing ${ }^{1}$, XU Hongtao ${ }^{1}$, FAN Xiying ${ }^{1}$ \\ ${ }^{1}$ Economic and Technical Research Institute of State Grid Shanxi Electric Power Company, Taiyuan, Shanxi Province, China
}

\begin{abstract}
The prefabricated cabin substation is a new type of intelligent substation integrating environmental protection, energy saving, high efficiency and economy. In view of the characteristics of the prefabricated cabin intelligent substation, its differences with conventional substations in terms of modularity and intelligent design are compared, the advantages of the prefabricated cabin substation are summarized, the key technology research of the cabin design is carried out, and its technical and economic indicators are analyzed. The research results show that, compared with conventional standardized substations, the use of prefabricated cabin substation mode can effectively improve the space utilization rate and the flexibility of station construction, the construction area can be reduced by $19 \%$, the construction period is shortened by about $30 \%$, and the cost is reduced by $5.35 \%$, which has good economic and practical value.
\end{abstract}

\section{Introduction}

Traditional urban substations have a long construction period and a large area, it is difficult to cope with the rapid increase in load. The construction land is restricted by topography and is inconsistent with the surrounding environment, which also increases the difficulty of site selection and construction of traditional substations.

The prefabricated cabin substation is a new type of intelligent substation, which is based on the improvement of outdoor box-type substation technology. The primary and secondary system equipment of the substation is installed in the factory after installation and commissioning. The cabin body is then transported to the site for assembly into a station, which realizes system integration, production factoryization, assembly modularization, and convenient construction[1]. The prefabricated cabin substation occupies a small area, has a high degree of integration, a flexible design, and a high degree of intelligence, which can better alleviate the above problems.

The earliest application of prefabricated cabin-type substations abroad was the complete set of outdoor substation equipment used in European countries in the 1960s. Subsequently, the United States and Japan introduced $33 \mathrm{kV}$ substations and $66 \mathrm{kV}$ substations using prefabricated cabin technology based on the concept of overall modularization respectively. In addition, the container-type electrical cabins promoted and used in the Middle East and Australia currently are also prefabricated cabin substations, which solve the problem of substation construction caused by special local climate and geographical conditions well[2], but it is mainly used to replace the secondary equipment compartment which the internal secondary equipment has not changed much[2]. This is quite different from the concept of factory processing and prefabricated construction in our country.

Mobile substation technology started relatively late in China. Our country has imported some pre-installed boxtype substations from other countries like France and Germany since the 1980s, and imported some box-type substations from the United States in the mid-1990s. During this period, domestic companies have accumulated experience while achieving the localization of box-type substations. After more than ten years of development, the concept of domestic distribution prefabricated cabin substation has been widely used in transformer equipment with voltage levels of $110 \mathrm{kV}$ and below, the technology is relatively mature, and the $220 \mathrm{kV}$ prefabricated cabin substation is also booming. As of 2017, there have been more than 600 prefabricated cabintype substations are under construction or have been put into use[3].

\section{Research on the characteristics of prefabricated cabin substation}

\subsection{Design and construction process of prefabricated cabin substation}

Conventional substations must complete the civil construction of the house and equipment foundations before proceeding with the electrical equipment installation, parallel construction is not possible, and the on-site operating environment is poor. It cannot meet the requirements of efficient and rapid construction of modern stations, and the quality cannot be effectively guaranteed. At the same time, the difficulty of equipment

\footnotetext{
*Corresponding author: 728130955@qq.com
} 
connection and debugging is increased. The design and construction process of a conventional substation is shown in Figure 1.

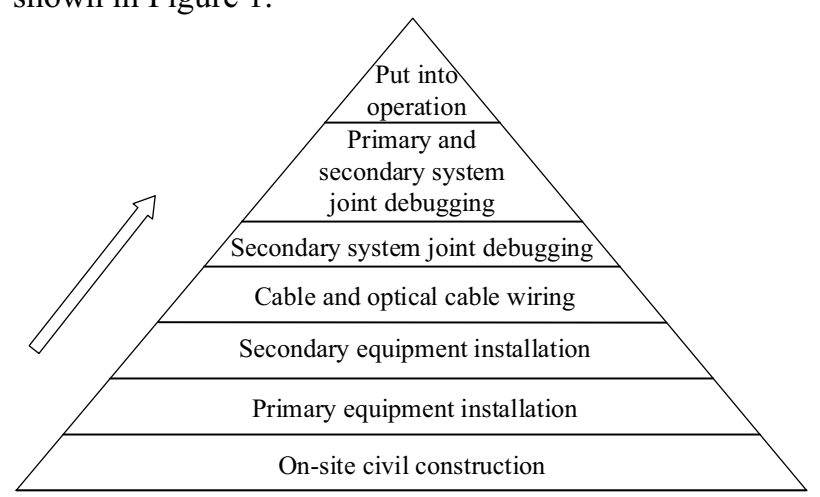

Figure 1. Construction process of conventional substation

The construction process of prefabricated cabin-type substation adopts the idea of parallel construction. While civil construction is carried out on site, the process of cabin production and equipment manufacturing, assembly and debugging can be carried out simultaneously in the factory, which effectively reduces the workload on site, shortens the construction period, and realizes the rapid construction of the substation.

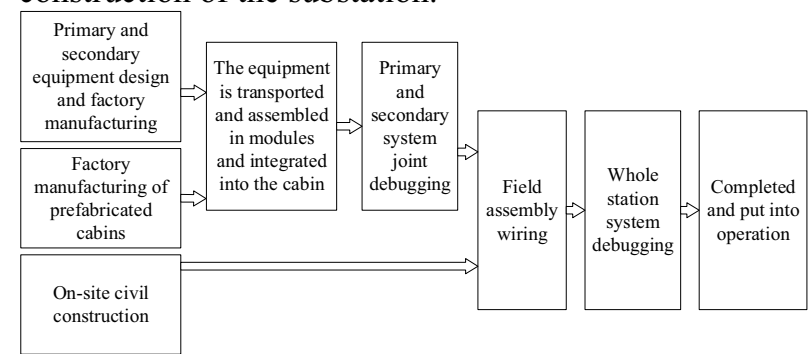

Figure 2. Construction process of prefabricated cabin substation

\subsection{Technical characteristics}

The prefabricated substation is mainly composed of civil engineering and electrical parts. Civil engineering modules include production complex, building walls, cable trenches, etc. Electrical modules include main transformers, outlets of various voltage levels, automation and other modules.

\subsubsection{Features of civil engineering module}

The following points should be fully considered when manufacturing substation civil engineering modules: 1) Carry out system planning according to local conditions, abolish traditional building structures, and reduce design, installation and commissioning period. 2) Reduce the wet construction of conventional engineering construction, transform it into industrialization, and quickly assemble it on-site according to the process standard after production inspection. 3) The cable trench can be prefabricated, and the fence and firewall are assembled, which is simple and quick to assemble on site; the main body of the comprehensive building adopts light steel structure and is directly installed on site, the prefabricated cabin can be directly fixed and installed on the civil foundation bolts after being transported to the site, which can greatly reduce the construction period [4].

\subsubsection{Features of electrical modules}

1) The main transformer is the same as the normal mode and is still arranged in the outdoor. Optimize the input and output terminals of the transformer, the secondary side is directly connected to the module through a pluggable connector, and the primary side uses a cable or overhead method, but the insulation and sealing performance must be ensured. 2) For $110 \mathrm{kV}$ and $220 \mathrm{kV}$ GIS equipment, due to its characteristics of highly integrated, the use of factory-prefabricated integral cable sleeves or pluggable cable connectors improves the convenience of installation, operation and maintenance. 3) For the $10 \mathrm{kV}$ input and output module, in recent years, the application of permanent magnet vacuum switch technology has made the switchgear significantly improved in terms of volume, weight, hoisting, maintenance, and transportation[4].

\subsection{Advantages}

The main advantages of the prefabricated cabin substation are as follows.

1) Reduce on-site operations and shorten the construction time. Adopting the concept of parallel construction, completing the production and installation and commissioning of equipment in the factory at the same time as civil construction, can greatly simplify the construction process.

2) Factory manufacturing to ensure the quality of equipment.

3) Pre-installation testing in the factory to achieve controllable quality and construction period.

4) The method of building a station is flexible, reducing terrain restrictions. The modular solution can flexibly configure the composition and layout of each module according to the different terrain, so as to adapt to the requirements of multi-scenario planning and construction, realize flexible station construction, and effectively reduce the cost of station construction.

5) Achieve the goal of environmental friendliness and green environmental protection[3].

\section{Key technology research}

\subsection{The cabin body radiation protection design}

Appropriate and reasonable system access methods and line paths should be selected in the design, and the underground cable methods should be used as much as possible. In the design of substations, the use of phaseseparated equipment is minimized, and three-phase equipment is used to make full use of the characteristics of three-phase electricity to cancel the electromagnetic fields generated by each phase. If split-phase equipment is to be used, the distance between phases should be shortened as much as possible during the design so that the electromagnetic field generated by the equipment of 
each phase can be offset to the maximum extent. In addition, reasonable measures should be used to shield the electromagnetic field, which has a significant shielding effect on power frequency electromagnetic radiation.

\subsection{Sound insulation design of substation}

Choose low-noise axial flow fans and silencing hundred pages, and strive to fundamentally reduce noise source pollution. The substation is designed as a cube with a regular shape and a double-layer sealed anti-corrosion structure box with good sealing and sound insulation. The greening work around the substation is done well, and it has better sound insulation and radiation protection while beautifying it.

\subsection{Requirements for cabin insulation and cold resistance}

The cabin wall is also an important part of the cabin manufacturing process. The wall should be made of flexible wall panels that are versatile and can be filled with a variety of fillers. A set of wall panels is composed of two door panels with the same external and internal dimensions. Each door panel is made of a metal plate with folded edges around it, forming a half-empty frame structure inside, and the empty frame is filled with rock wool or polyurethane or other fire-proof insulation materials to meet the needs of different users. Each set of inner and outer door panels adopts the back-to-back installation method, through the misalignment design of the inner and outer mounting screws, and adds a circle of waterproof sealing rubber pads to the joint surface of the inner and outer pillars and the wall panels to fix the inner and outer door panels to the cabin structure. On the column, a "four-layer" cabin wall with two layers of metal structure and two layers of thermal insulation is formed. All wall panels are designed to a uniform size, which is convenient for mass production and interchange, forming a highly versatile, thermal insulation modular cabin wall with controllable performance, waterproof and reliable strength [5].

\section{Technical and economic indicators}

Based on Shanxi Province, this article evaluates the economic benefits of $220 \mathrm{kV}$ pre-installed GIS outdoor substations from the aspects of construction period, total project volume, floor space, equipment costs, installation costs, and operation and maintenance costs.

\subsection{Construction period}

The main equipment of $220 \mathrm{kV}$ prefabricated GIS outdoor substation includes intelligent transformer, prefabricated cabin $220 \mathrm{kV}$ GIS power distribution device module, prefabricated cabin $110 \mathrm{kV}$ GIS power distribution device module, $10 \mathrm{kV}$ switch cabinet prefabricated cabin, reactive power compensation prefabricated cabin, and prefabricated secondary combination equipment and living prefabricated cabins, etc., the construction cycle includes the construction cycle of factory processing of main equipment, on-site modular assembly, inspection and testing.

The on-site construction period of $220 \mathrm{kV}$ conventional GIS outdoor substation and $220 \mathrm{kV}$ preinstalled GIS outdoor substation are compared. The civil construction period of the substation civil works below zero meters is not much different from the original site. The construction period of the on-site construction on the ground part is saved by building houses, firewalls, fences, cable trenches and other projects. Among them, the main building and the cable trench have a certain impact on the total construction period of the project, the firewall, fence and other items do not affect the total construction period of the project. The analysis of construction period technical indicators is shown in Figure 3. The ratio of shortened construction period of $220 \mathrm{kV}$ prefabricated GIS outdoor substation compared with conventional smart GIS outdoor substation is shown in Figure 4.

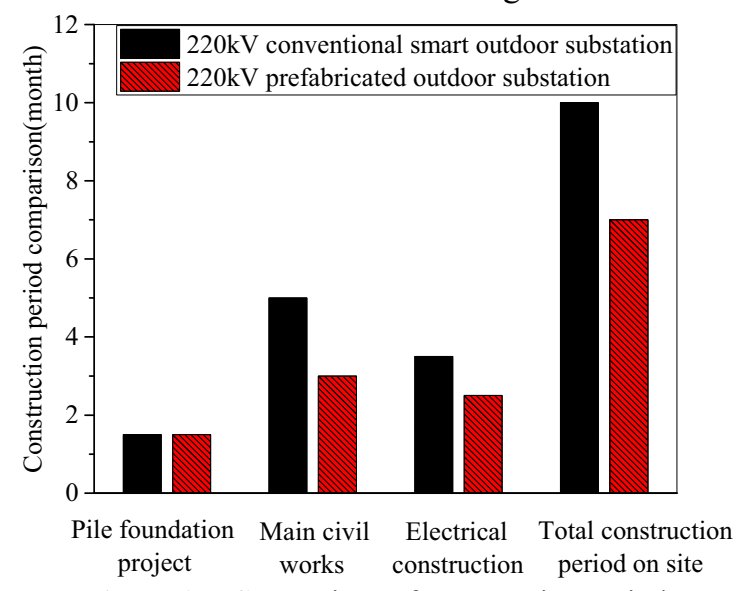

Figure 3. Comparison of construction period

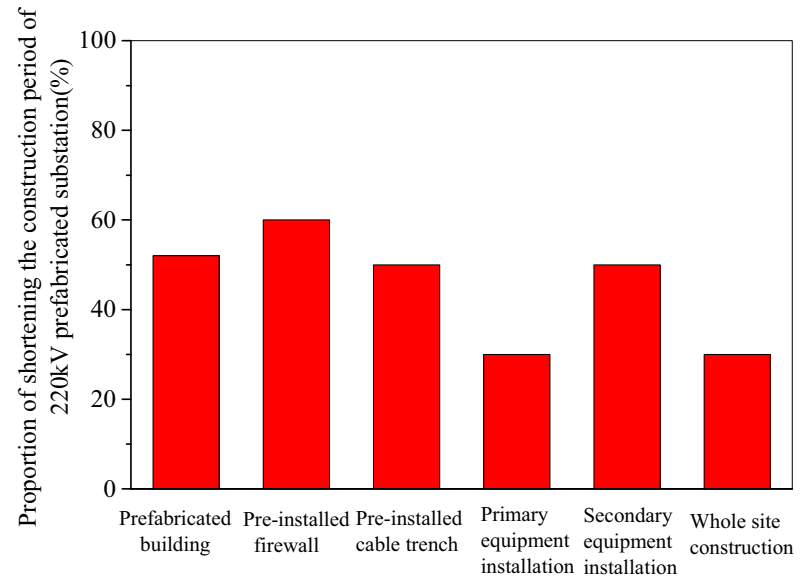

Figure 4. Proportion of shortened construction period of $220 \mathrm{kV}$ prefabricated outdoor substation

It can be seen from Figure 3 and Figure 4 that compared with the conventional $220 \mathrm{kV}$ smart GIS outdoor substation, the construction period of the $220 \mathrm{kV}$ pre-installed GIS outdoor substation can be saved by 3 months in total, and the construction period of each project has been shortened by $30 \% \sim 60 \%$. The overall construction period of the station has been shortened by about 30\%. 


\subsection{Total project}

Figure 5 shows the comparison of the total amount of onsite projects.

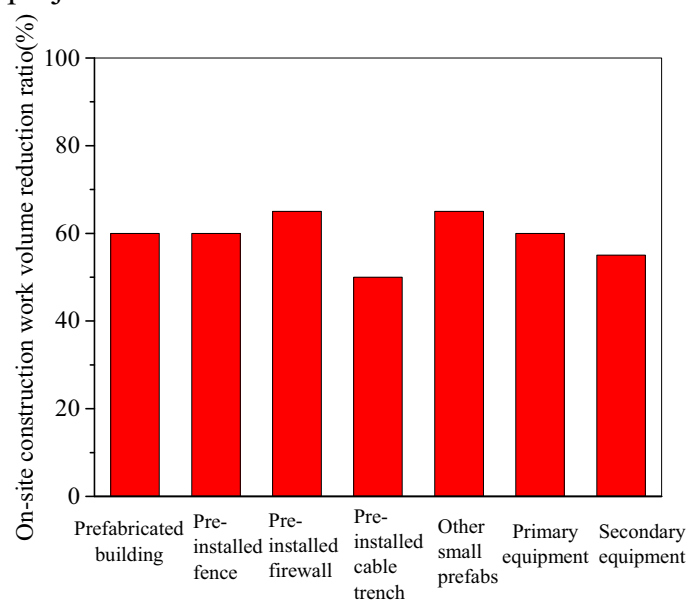

Figure 5. Comparison of field engineering quantity

It can be seen from Figure 5 that the total amount of on-site construction of prefabricated structures has been greatly reduced, generally around $55 \%$ to $65 \%$.

\subsection{Technical and economic indicators}

The comparison of the area occupied by $220 \mathrm{kV}$ preinstalled GIS outdoor substation and conventional $220 \mathrm{kV}$ smart GIS outdoor substation is shown in figure 6 . The application of pre-installed $220 \mathrm{kV}$ and $110 \mathrm{kV}$ GIS power distribution device modules, pre-installed switchgear modules, and pre-installed secondary combination equipment modules in prefabricated substations reduces the floor space in the enclosure by $10.28 \%$ and the building area by $19 \%$, which can save land resources, land acquisition investment, and increase the rate of return on investment.

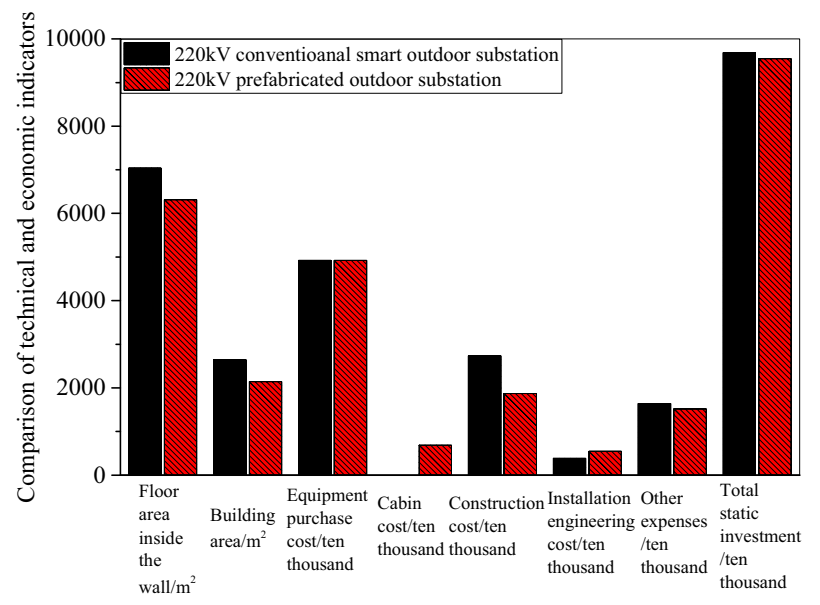

Figure 6. Comparison of technical and economic indicators

The prefabricated substation is prefabricated and assembled in the factory, so it increases the workload of modular equipment transportation, site hoisting and assembly. The installation cost is slightly higher than the conventional plan, but it reduces the workload of site assembly and commissioning, and saves installation and transportation. The maintenance time has shortened the construction period of the substation. Compared with the conventional scheme, $220 \mathrm{kV}$ and $110 \mathrm{kV}$ use pre-installed GIS power distribution devices, and $10 \mathrm{kV}$ switch cabinets use miniaturized equipment installed in prefabricated cabins. At the same time, the control building is eliminated, and the pre-installed secondary combined equipment is used. Design and maintenance cycle is not less than 20 years, which is higher than conventional equipment. With the improvement of equipment reliability, operation and maintenance workload, and operation and maintenance costs will be greatly reduced.

\section{Conclusion}

This paper analyzes the characteristics of $220 \mathrm{kV}$ prefabricated cabin-type substation, and proposes three key technology researches. Taking Shanxi Province as an example, the technical and economic indicators are evaluated. Compared with $220 \mathrm{kV}$ conventional GIS substation, the construction plan of $220 \mathrm{kV}$ prefabricated outdoor GIS substation can shorten the construction period by $30 \%$, reduce the total project volume by $55 \%$ to $65 \%$, and reduce the area of the substation by $10.28 \%$. It can be seen that the pre-installed $220 \mathrm{kV}$ outdoor GIS substation is economically superior to the conventional $220 \mathrm{kV}$ outdoor GIS substation, which fully reflects the requirements of saving, environmental protection and industrialization, and has good application and promotion value.

\section{References}

1. LI Zheng. Research and application of design, installation and commissioning technology of $220 \mathrm{kV}$ assembled intelligent substation. Southeast University. (2019)

2. ZHANG Daqing. Module Optimization design method for Prefabricated Cabin. Design and development. (2018)

3. CAI Jing. Research on Design and Construction of Prefabricated Substation. Journal of North China University. (2019)

4. XU Su, FANG Chaoz, ZHANG Wei, Qu Maoqian, GUO Houjin, GENG Zhi. Comparative Analysis of Economic Benefits of $220 \mathrm{kV}$ Prefabricated Substation. Electrical technology. (2018)

5. ZHAO Lu, LI Fang. Research on Scheme and Key Technology of Distribution Substation with Prefabricated Cabin. Hydropower Engineering. (2017) 